\title{
Differential Effects of Ang-2/VEGF-A Inhibiting Antibodies in Combination with Radio- or Chemotherapy in Glioma
}

\author{
Gergely Solecki 1,2,3, Matthias Osswald 1,2, Daniel Weber ${ }^{2}$, Malte Glock ${ }^{2}$, Miriam Ratliff ${ }^{1,4}$, \\ Hans-Joachim Müller ${ }^{5}$, Oliver Krieter ${ }^{5}$, Yvonne Kienast ${ }^{5}$, Wolfgang Wick ${ }^{1,2}$ and \\ Frank Winkler 1,2,* \\ 1 Neurology Clinic and Neurooncology Program at the National Center for Tumor Disease, University \\ Hospital Heidelberg, Im Neuenheimer Feld 400, 69120 Heidelberg, Germany; gergely.solecki@web.de (G.S.); \\ matthias.osswald@med.uni-heidelberg.de (M.O.); Miriam.Ratliff@umm.de (M.R.); \\ wolfgang.wick@med.uni-heidelberg.de (W.W.) \\ 2 German Cancer Consortium (DKTK), Clinical Cooperation Unit Neurooncology, German Cancer Research \\ Center (DKFZ), 69120 Heidelberg, Germany; daniel.weber97@gmx.de (D.W.); malte.glock@web.de (M.G.) \\ 3 Business Unit Service and Customer Care, Carl Zeiss Microscopy GmbH, 07745 Jena, Germany \\ 4 Neurosurgery Department, University Medical Center Mannheim, 68167 Mannheim, Germany \\ 5 Pharmaceutical Research and Early Development (pRED), Roche Innovation Center Munich, 82377 Munich, \\ Germany; hans-joachim.mueller@mnet-mail.de (H.-J.M.); Oliver.Krieter@roche.com (O.K.); \\ yvonne.kienast@roche.com (Y.K.) \\ * Correspondence: frank.winkler@med.uni-heidelberg.de; Tel.: +49-0-6221/56-7396
}

Received: 31 December 2018; Accepted: 28 February 2019; Published: 6 March 2019

\begin{abstract}
Antiangiogenic strategies have not shown striking antitumor activities in the majority of glioma patients so far. It is unclear which antiangiogenic combination regimen with standard therapy is most effective. Therefore, we compared anti-VEGF-A, anti-Ang2, and bispecific anti-Ang-2/VEGF-A antibody treatments, alone and in combination with radio- or temozolomide (TMZ) chemotherapy, in a malignant glioma model using multiparameter two-photon in vivo microscopy in mice. We demonstrate that anti-Ang-2/VEGF-A lead to the strongest vascular changes, including vascular normalization, both as monotherapy and when combined with chemotherapy. The latter was accompanied by the most effective chemotherapy-induced death of cancer cells and diminished tumor growth. This was most probably due to a better tumor distribution of the drug, decreased tumor cell motility, and decreased formation of resistance-associated tumor microtubes. Remarkably, all these parameters where reverted when radiotherapy was chosen as combination partner for anti-Ang-2/VEGF-A. In contrast, the best combination partner for radiotherapy was anti-VEGF-A. In conclusion, while TMZ chemotherapy benefits most from combination with anti-Ang-2/VEGF-A, radiotherapy does from anti-VEGF-A. The findings imply that uninformed combination regimens of antiangiogenic and cytotoxic therapies should be avoided.
\end{abstract}

Keywords: Ang-2; antiangiogenic therapy; in vivo imaging; radio- and chemotherapy; VEGF-A

\section{Introduction}

Glioblastoma (GB) is the most common and most malignant adult primary brain tumor [1]. It is associated with a poor prognosis and a high burden for the patient. The standard treatment is maximum safe resection, followed by radiotherapy and concomitant and adjuvant temozolomide (TMZ) chemotherapy. Despite this intensive treatment, overall survival (OS) remains under two years [2], largely because of inherent tumor resistance mechanisms [3-5]. Therefore, better therapeutic 
strategies are urgently needed, which includes those that make standard radio- and chemotherapy more efficient.

GBs are characterized by dense but structurally and functionally abnormal blood vessels, which are driven by a high level of proangiogenic factors, particularly VEGF-A [6-8] and Angiopoietin 2 (Ang-2) [9-12]. Ang-2 inhibition has previously been described to increase the effectiveness of anti-VEGF-A therapy in glioma [9-11,13].

The aberrant glioma blood supply is likely to compromise the effects of radio- and chemotherapy in malignant gliomas: due to high levels of tumor hypoxia [6] and potentially also by reduced delivery of TMZ to the glioma cells [14]. Thus, reestablishment of a more physiological microvascular function by antiangiogenic therapies, called vascular normalization, might increase the effectiveness of radioand/or chemotherapy in gliomas [6,15-18]. This concept is supported from clinical data outside the brain, where combination of anti-VEGF-A therapies with chemotherapy showed the best antitumor effectivities $[19,20]$. However, in two phase III clinical trials in frontline GB (AVAglio and RTOG 0825) where standard radiochemotherapy was combined with the anti-VEGF-A antibody bevacizumab (Avastin ${ }^{\circledR}$, Genentech Inc., South San Francisco, CA, USA), progression free survival (PFS), was improved by 4.4 months, while OS was unchanged [21,22]. Similar results were obtained in the EORTC 26101 study where bevacizumab was combined with lomustine chemotherapy vs. lomustine alone in patients with progressive GB [23]. Together these results unequivocally confirm that bevacizumab activity in controlled clinical trials remains far below expectations in newly diagnosed and relapsed GB.

The reason for that is not clear. Next to the possibility that only subgroups of GB patients benefit $[4,24,25]$, other explanations for the so far disappointing overall benefits of anti-VEGF-A therapy include: (1) suboptimal vascular normalization of single VEGF-A inhibition, which is insufficient to increase the effectiveness of cytotoxic therapy and (2) lack of synergy or even detrimental effects for the combination with cytotoxic therapy. For chemotherapy, for example, vascular normalization with partial re-erection of the blood-brain barrier might compromise tumor penetration of the drug.

Therefore, to increase the benefit from antiangiogenic treatment strategies in glioma, it appears necessary to test these two possibilities: by directly comparing how inhibitors of VEGF-A, Ang-2, and both affect multiple critical parameters of tumor biology, and, most importantly, whether that benefits concomitant chemotherapy, radiotherapy, or both. Therefore, in this study we provide such a comprehensive comparison, making use of a newly developed multi-parameter longitudinal in vivo multi-photon microscopy technology. The results speak for a complex and dynamic system of interactions between the treatment modalities, and finally suggest that anti-Ang-2/VEGF-A is the best combination partner for chemotherapy, but anti-VEGF-A for radiotherapy.

\section{Results}

\subsection{A Dynamic Multi-Parameter Microscopy Model to Study Therapeutic Interactions}

To achieve parallel inhibition of both human and mouse VEGF-A and Ang-2, a bispecific antibody was used that employed the CrossMab technology [10,11,26-28] (the humanized antibody is vanucizumab [29,30]), combining the anti-Ang-2 specific IgG1 antibody LC06 with the anti-VEGF-A antibody B20.4.1 [31]. To directly compare the effects of VEGF-A, Ang-2, and dual inhibition on glioma biology, we tested the effects of these three antibodies vs. control antibody in an identical, clinically relevant dose ( $5 \mathrm{mg} / \mathrm{kg}$ BW every third day) (for treatment groups, see Figure S1A). To follow both morphology and pathophysiological features of glioma cells and tumor blood vessels alike, which would allow deeper insights into the complex world of interactions during the different combination therapies, we established a novel in vivo two-photon microscopy technology. This experimental setup made it possible to determine multiple parameters in the same tumor over multiple time points (Figure S1B). 


\subsection{Differential Vascular Effects of Antiangiogenic Combination Regimens}

Dynamic angiograms of the same glioma region over time revealed striking morphological changes indicative of vascular normalization with anti-Ang-2/VEGF-A: blood vessels became thinner, much more ordered, and a clearer hierarchy developed, better resembling blood microvessels of the normal brain (Figure 1A). In contrast, both anti-VEGF-A and anti-Ang-2 monotherapy caused antiangiogenic changes of the tumor vasculature, reducing the number of newly built blood vessels over time when compared to tumors treated with the control antibody, but a clear morphological normalization of the existing tumor vasculature was not evident (Figure 1A). In line with this finding, the microvascular blood flow velocity, a good integrative parameter to measure tumor hemodynamics [32] and a particular robust one to determine functional vascular normalization [7] was decreasing in control tumors over time, while only dual Ang-2/VEGF-A inhibition rescuing levels to those seen in normal brain (Figure 1B). Remarkably, this was different when the antiangiogenic antibodies were combined with radiotherapy, where only anti-VEGF-A achieved a significant normalization of blood flow velocities compared to controls (Figure 1C), while in combination with chemotherapy it was again anti-Ang-2/VEGF-A that stood out as vascular normalization strategy (Figure 1D). Functional vascular normalization was paralleled by morphological vascular normalization in these distinct combination regimens (anti-VEGF-A plus RT, Suppl. Figure 2A; anti-Ang-2/VEGF-A plus chemotherapy, Figure S2B).

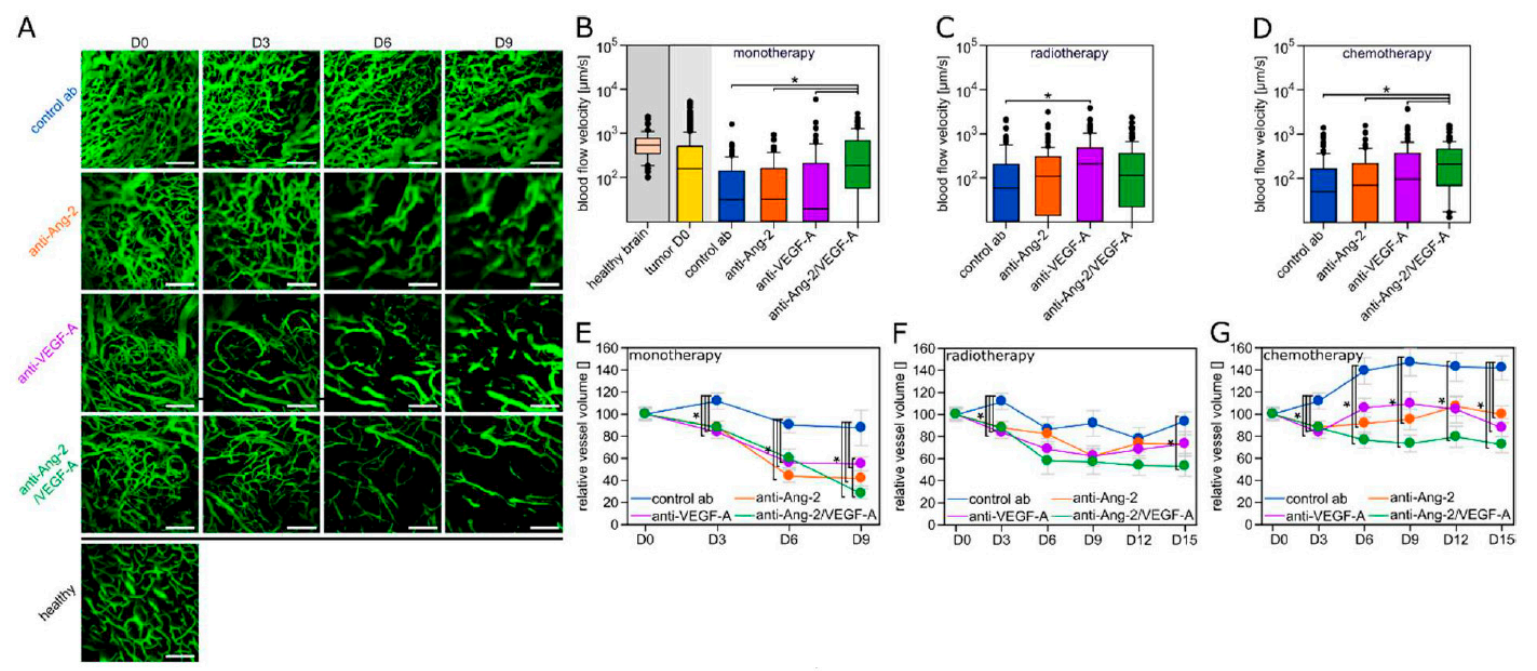

Figure 1. Vascular parameters for antiangiogenic treatment groups in monotherapy, and in combination with radio- or chemotherapy. (A) Representative angiograms for control, anti-Ang-2, anti-VEGF-A, and anti-Ang-2/VEGF-A monotherapy in comparison to healthy brain vasculature. Note that morphological vascular normalization occurs preferentially on days three and six under anti-Ang-2/VEGF-A dual inhibition. Scale bars: $150 \mu \mathrm{m}$. (B-D) Microvascular blood flow velocity in the healthy brain, in tumor blood vessels at the beginning of therapy (tumor D0), and on D6 in all four treatment groups. (B) Without cytotoxic combination partner; (C) in combination with radiotherapy; (D) in combination with TMZ chemotherapy. A total of 68-112 vessels from 5-11 animals per group were quantified. Box plots representing median values with 10th, 25th, 75th, and 90th percentiles. ${ }^{*} p<0.05$ one-way ANOVA on ranks and post hoc Dunn's test. (E-G) Vessel volume over time for the different antiangiogenic antibodies given without cytotoxic therapy (E) or in combination with radiotherapy $(\mathbf{F})$ or chemotherapy $(\mathbf{G})$. Overall, 11-23 regions from 6-12 animals per group. Data are expressed as mean $\pm \mathrm{SD}$. ${ }^{*} p<0.05$ one-way ANOVA and post hoc Tukey test.

As a point of caution, it has been a long matter of debate whether the effects of vascular normalization can actually help the tumor cells gain better access to oxygen and nutrients, thereby creating unwanted effects. Indeed, when quantifying the occurrence of mitotic figures in glioma 
cells in vivo, we found that antiangiogenic treatments lead to a short-time "burst" of glioma cell proliferation that ceased at later time points and was not present when antiangiogenic agents where combined with chemo- or radiotherapy (Figure S3A-D).

The total microvascular volume was reduced by all three antiangiogenic agents, as monotherapies and in all combinations with chemo- or radiotherapy; consistently, the strongest long-term reductions were seen with anti-Ang-2/VEGF-A (Figure 1E-G; compare also Figure 1A and Figure S2A,B). Of note, this effect was most evident in combination with chemotherapy (Figure 1G).

Together, this data speaks for differential activities of the three antiangiogenic antibodies on important parameters of tumor vascularization and, unexpectedly, for partially divergent effects when they are combined with radio- or chemotherapy.

\subsection{Tumor Growth Inhibition is Limited to Regimens Where Vascular Normalization Occurs}

Tumor growth over time was determined through the cranial window by measuring the area occupied by RFP-positive glioma cells, ensuring that real anti-tumor and not mere anti-edema effects were assessed. Furthermore, we ruled out that anti-edema effects of antiangiogenic therapies influence measurements of gross tumor size by demonstrating that density of tumor cell nuclei in a given tumor volume does not change during all three antiangiogenic treatments (Figure S3E,F).

All three antiangiogenic therapies did not significantly slow down tumor growth when given without a cytotoxic combination partner (Figure 2A). When combined with radiotherapy, anti-VEGF-A showed strongest tumor growth inhibition, significantly better than with anti-Ang-2/VEGF-A (Figure 2B). This reflects the superiority of this combination regimen regarding vascular normalization (Figure 1C, Figure S1A). In contrast, TMZ chemotherapy was most effective when combined with anti-Ang-2/VEGF-A (Figure 2C), again matching the strongest vascular normalization seen with this combination regimen (Figure 1D, Figure S2B).
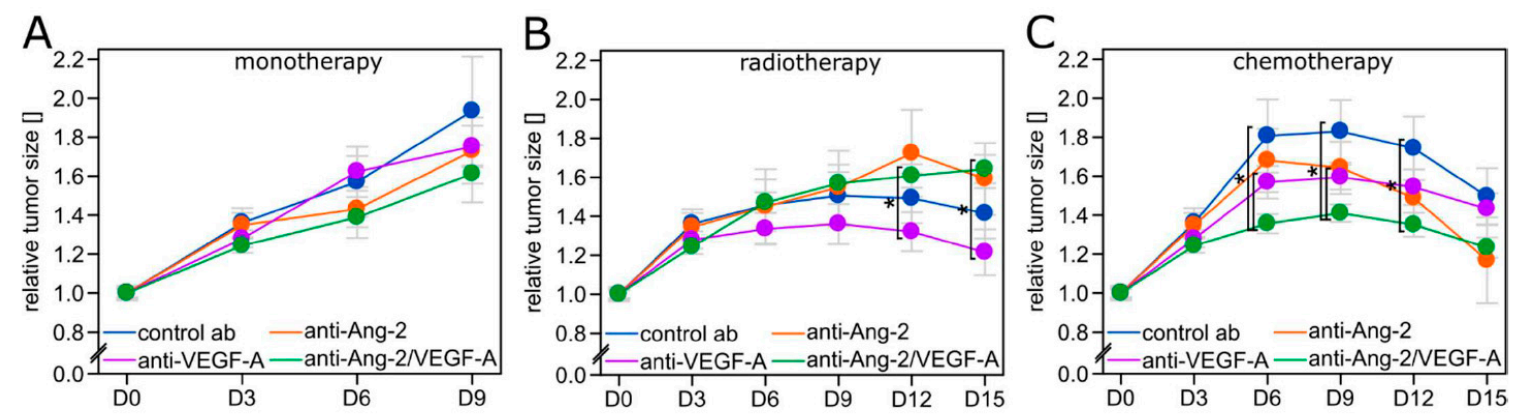

Figure 2. Tumor size over time. Brain tumor size as measured through the cranial window over time in 6-7 animals per group. Antiangiogenic therapy without cytotoxic therapy (A) or in combination with radiotherapy $(\mathbf{B})$ or temozolomide (TMZ) chemotherapy $(\mathbf{C})$. Data are expressed as mean \pm SEM. ${ }^{*} p<0.05$ two-tailed Student's $t$-test.

\subsection{Tumor Cell Death Patterns Suggest Improved TMZ Penetration}

We have demonstrated before that VEGF pathway inhibition improves the antitumor effects of radiotherapy in glioma due to increased tumor oxygenation during vascular normalization [6]. To get indications whether vascular normalization also helps TMZ chemotherapy by improving tumor penetration of the drug, we analyzed the occurrence of nuclear changes indicative of cell death with respect to blood vessel proximity in all combination regimens in vivo over time. For that we exploited that in addition to cytoplasmatic RFP, glioma cells stably expressed both RFP in the cytoplasm, and GFP in the nucleus.

Added to radiotherapy, anti-VEGF-A, the strongest vascular normalization regimen in this combination, did not significantly modify the distance of pathological events in relation to perfused blood vessels (Figure 3A,B). In contrast, when combined with chemotherapy, anti-Ang-2/VEGF-A, 
but also anti-VEGF-A, did significantly increase the median distance of pathological nuclei to the nearest blood vessel, compared to the control antibody (Figure 3A,B). Together, this data supports the concept that vascular normalization can increase the effectivity of chemotherapy by allowing better drug penetration to the glioma cells.

A

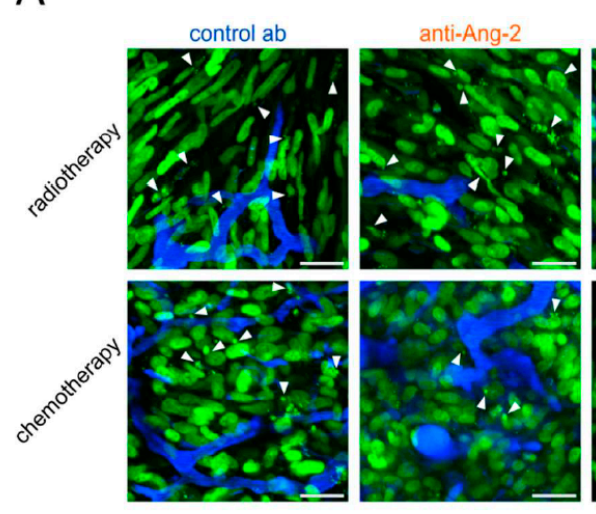

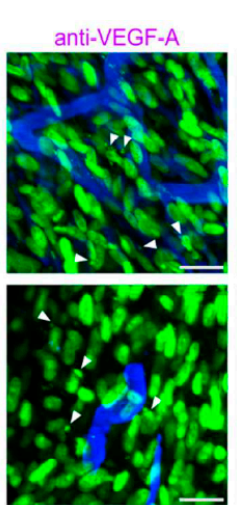

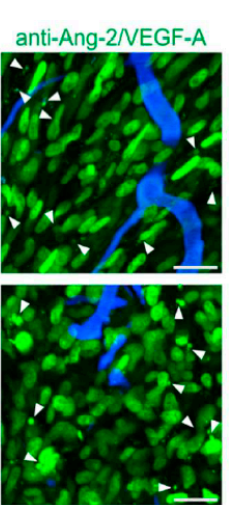

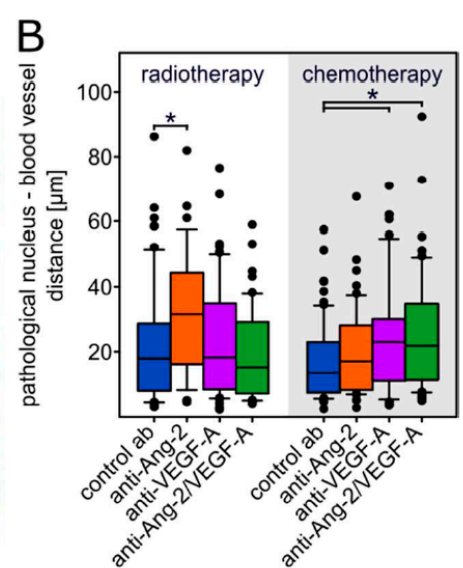

Figure 3. Dynamic changes of tumor cell nuclear parameters. (A) Representative images of pathological nuclei in dependence from the vessel distance. Green fluorescent protein (GFP) expressing nuclei are shown in green and the tumor vasculature is visualized in blue. The small arrows are only highlighting typically pathological nuclei. Scale bars: $20 \mu \mathrm{m}$. (B) Distance of the pathological nuclei from the proximal vessel on D9. A total of 35-68 cells from 4-7 animals per group were quantified. Box plots representing median values with 10 th, 25 th, 75 th, and 90 th percentiles. ${ }^{*} p<0.05$ one-way ANOVA on ranks and post hoc Dunn's test.

\subsection{Tumor Microtube Formation and Cellular Motility Closely Reflect Divergent Responses to Combination Regimens}

We have recently discovered that glioma cells extend ultra-long cellular extensions, called tumor microtubes (TMs), to interconnect with each other to a multicellular network in which tumor cells resists the harmful effects of radiotherapy. TMs even increase in response to radiotherapy [3]. Therefore, the occurrence and length of TMs under different therapy strategies was determined on D0, D9, and D28 after the start of the antiangiogenic treatment (Figure 4A-D). In combination with radiotherapy, anti-Ang-2 and anti-Ang-2/VEGF-A both increased TM formation, while anti-VEGF-A (the optimum combination partner) did not. Likewise, in combination with chemotherapy, the ideal combination partner anti-Ang-2/VEGF-A, and also anti-VEGF-A, reduced TM length over time, compared to control and anti-Ang-2 antibodies.

One possible unwanted effect of antiangiogenic therapy is increased tumor cell invasiveness (Figure 4E) [33-36]. Anti-Ang-2/VEGF-A monotherapy slightly reduced nuclear motility, compared to control and the two other antiangiogenic antibodies (Figure 4F). While anti-Ang-2 and anti-Ang-2/VEGF-A increased motility compared to control when combined with radiotherapy, anti-VEGF-A did not (Figure 4G). In contrast, in combination with chemotherapy, anti-VEGF-A failed to reduce nuclear motility, but anti-Ang-2/VEGF-A and anti-Ang-2 did (Figure 4H). 

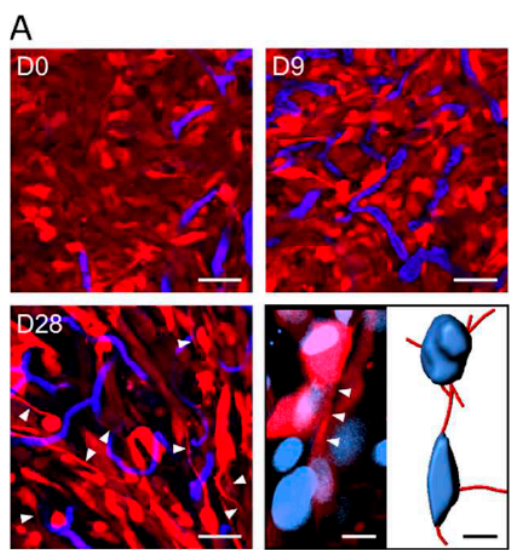

E
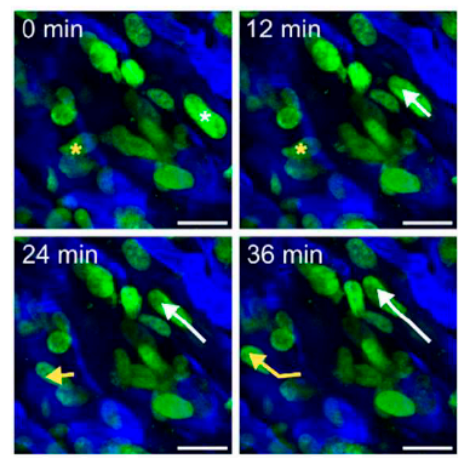

B
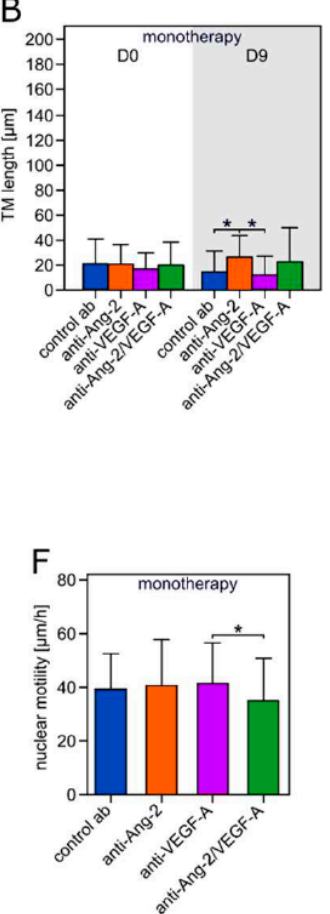

C

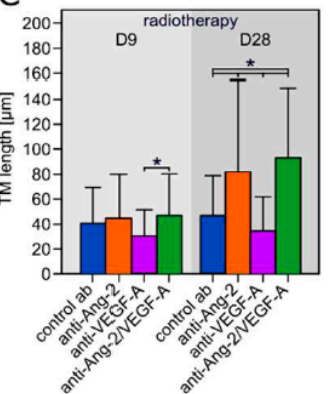

$\mathrm{D}$
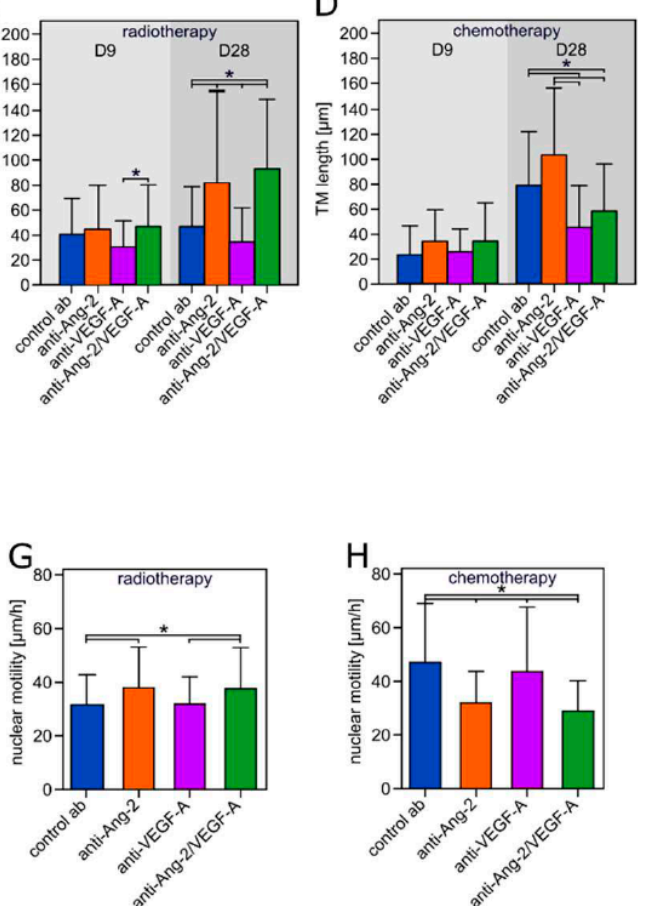

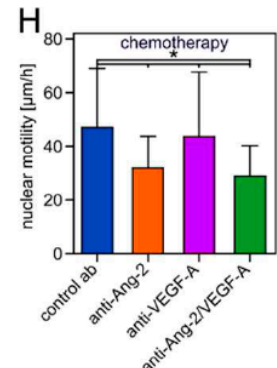

Figure 4. Tumor microtubes (TM) development and tumor cell motility. (A) Representative images of cellular morphology including TM development for the control antibody plus TMZ chemotherapy group. Note development of long cellular protrusions of 1-2 $\mu \mathrm{m}$ diameter, which is consistent with the criteria of TMs. Lower right panel: 3D reconstruction of TM-mediated glioma cell connections. Scale bars: $50 \mu \mathrm{m}$ and $10 \mu \mathrm{m}$ (right lower corner). (B-D) TM length for antiangiogenic monotherapy, and combinations with radiotherapy or chemotherapy. $n=60$ cells from 3 animals per group. (E) Representative tracks of the movement of two nuclei over $36 \mathrm{~min}$. Scale bars: $25 \mu \mathrm{m}$. (F-H) Velocity of tumor cell nuclei for the monotherapy and the combined treatment with irradiation or TMZ. $n=60-140$ nuclei from 3-7 animals per group. Data are expressed as mean \pm SD. ${ }^{*} p<0.05$ one-way ANOVA on ranks and post hoc Dunn's test.

\section{Discussion}

In this study, we conducted a characterization of different antiangiogenic strategies in combinations with radio- and chemotherapy in glioblastoma. We found that anti-VEGF-A was the optimal combination partner for radiotherapy, while a bispecific antibody inhibiting both Ang-2 and VEGF-A was the best for chemotherapy throughout multiple parameters of tumor progression and therapy resistance. Importantly, there was an excellent correlation with morphological and functional vascular normalization $[6,14,18]$, supporting that this concept has therapeutic relevance for primary brain tumors. Unexpectedly, the cytotoxic combination partner (chemo- vs. radiotherapy) had profound influence on how the antiangiogenic treatments influenced the different parameters of tumor biology, frequently even producing opposite effects (Figure 5).

It has been demonstrated before that the VEGF and angiopoietin pathways are interrelated in glioma, making dual inhibition a plausible strategy. In patients with recurrent GB treated with bevacizumab, plasma Ang-2 concentrations were significantly increased at the time of relapse, pointing towards a potential role of Ang-2 in the development of resistance against VEGF-A targeting treatments [37]. This supports previous preclinical reports that Ang-2 upregulation is typically found during VEGF pathway inhibition [6,9,38]. Furthermore, a particular strong vascular normalization during co-inhibition of the VEGF-A and Ang-2 pathways is also supported by recent preclinical 
findings [9,11]. Moreover, dose-dependent effects of antiangiogenics need to be taken into account, which can reach from merely normalization effects in lower doses to frank vascular pruning in higher doses, including differential effects on cancer cells [7,14]. The dose selected for this study was a lower dose, which is however still in the range of doses given to patients, were a maximum effect on vascular normalization could be expected, and less vascular regression.
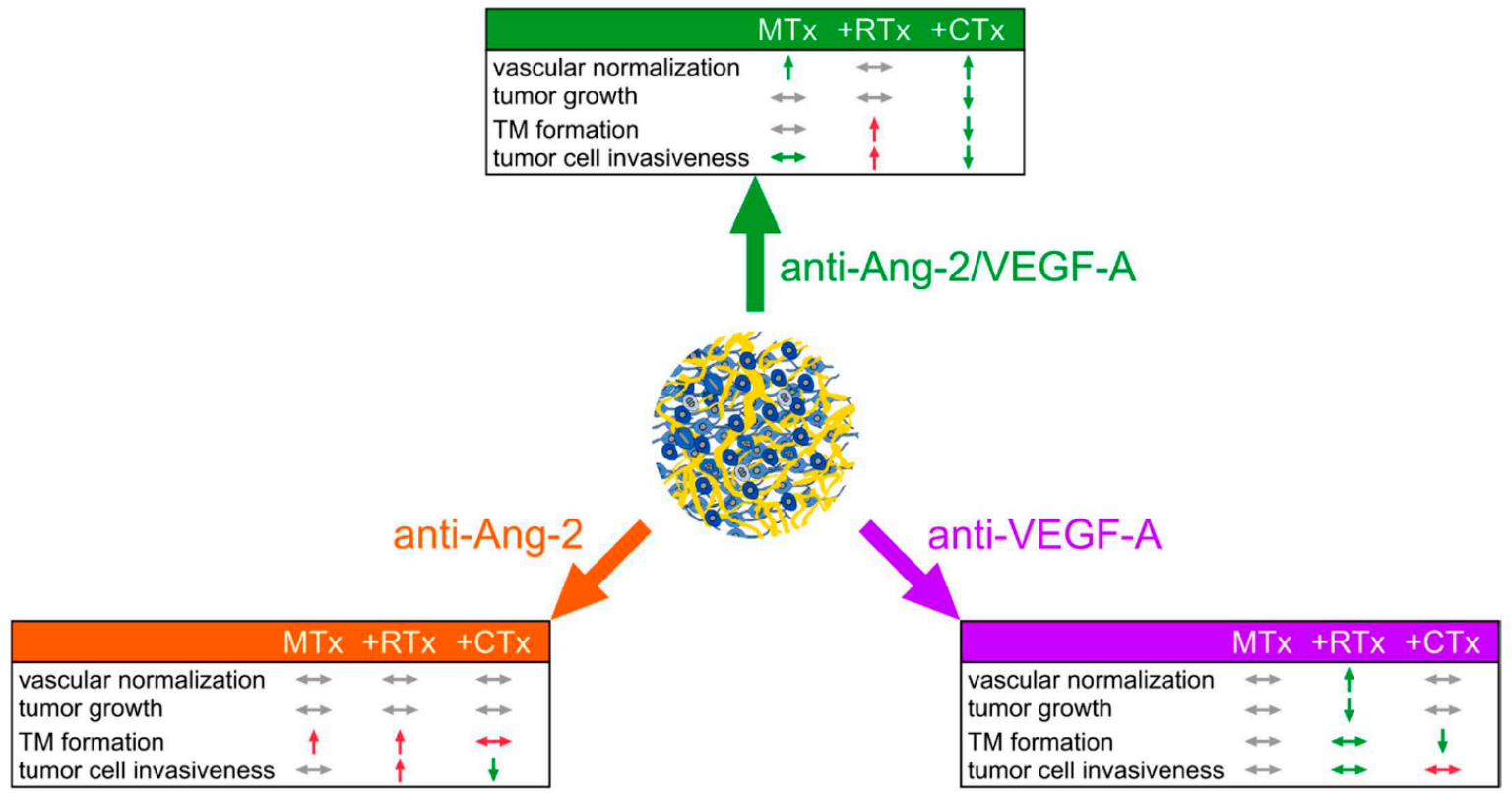

Figure 5. Summary of results. Schematic summary of the different experimental groups: antiangiogenic treatments as monotherapy or in combination with radiotherapy or chemotherapy for the most important parameters. Arrows down: parameter is decreased; arrows up: parameter is increased; sideways arrows: parameter is not affected; green arrows: beneficial effect compared to the other treatment groups; red arrows: unwanted effect compared to the other treatment groups; grey arrows: no effect compared to the other treatment groups.

However, dual inhibition of VEGF-A and Ang-2 did only improve the effects of TMZ chemotherapy, which included multiple favorable effects on parameters of glioma progression and therapy resistance. We demonstrate that nuclear changes indicative of glioma cell regression are not limited to the direct perivascular region in this combination anymore, supporting improved tumor penetration of TMZ by anti-Ang-2/VEGF-A co-inhibition. One can wonder why vascular normalization with re-erection of the blood-brain barrier is helping chemotherapy at all. In fact, contradictory findings have been reported whether antiangiogenic therapy improves chemotherapy penetration into the tumor or even hinders it [39-44]. However, TMZ is well known to effectively cross the blood-brain barrier (BBB) [45], which is the likely reason why it had similar clinical effects when compared to standard radiotherapy in a recent phase III study of low-grade glioma, where relevant BBB breakdown is normally not present [46]. With such a chemotherapeutic agent, BBB re-erection of any antiangiogenic treatment should be of minor relevance, and better drug delivery to the tumor by increase of its normally low blood flow velocity, but also by decrease of its high interstitial fluid pressure and other pathophysiological tumor features [14] during vascular normalization are likely to improve cytotoxic drug effectiveness. This view is supported by the findings of our study, where anti-Ang-2/VEGF-A was the only antiangiogenic treatment that normalized tumor blood vessels when combined with TMZ chemotherapy, and also significantly reduced tumor growth. Limitations remain. The tumor growth delay detected here might not translate into improved patient survival and the anti-edema effects of antiangiogenics may have clinical benefit even if the tumor load is increasing [47].

VEGF-A is responsible for the stimulation of proliferation and migration of endothelial cells and the enhancement of the vascular permeability [48]. Gliomas and other tumors often show highly 
elevated expression levels. For this reason, the therapeutic inhibition of this pathway was an important advance and is now targeted for a broad range of cancer entities [26,49]. However, further studies demonstrated that the efficacy of VEGF-A inhibition could be compromised by up-regulation of other angiogenic pathways [50]. One important component of this resistance is Ang-2, which is promoting neovascularization and tumor growth by Tie2 signaling in a VEGF-A independent manner [51-53]. While the single inhibition of Ang-2 led to a modest (if at all) beneficial effect on tumor growth and vascular normalization, which is in line with our results, the dual inhibition of both VEGF-A and Ang-2 proved beneficial for the therapy of CNS [9-11] and non-CNS [26,29,54-59] tumors.

In this study, we provide additional data in which opposite effects of anti-VEGF-A vs. anti-Ang-2 vs. dual inhibition on glioma growth are evident, depending on whether standard chemotherapy or standard radiotherapy is used as the combination partner. This might be best explained by three observations. First, chemotherapy and radiotherapy by themselves (without an active antiangiogenic combination partner) modulate blood vessel morphology, with antiangiogenic, anti-vascular, and partially also vascular normalization effects (control antibody groups: Figure S2, compared to Figure 1A) [60-62]. This can explain that the overall change of vascular morphology and function is somewhat unpredictable when an antiangiogenic agent is added. Second, the resulting differential vascular normalization effects observed with the various combination regimens can lead to various levels of tumor hypoxia, which is known to increase resistance to radiotherapy and TMZ [6,14-18]. Lastly, an additional or alternative explanation can be sought in our finding that relevant parameters of tumor resistance (e.g., TM formation, cellular invasiveness) are divergently increased or decreased. It has been described that radiotherapy can increase glioma cell invasiveness $[63,64]$ as one potential mechanism. Importantly, both radio- and chemotherapy can increase the number of TMs and their interconnections and the multicellular networks formed by TMs in gliomas are prime factors of primary and adaptive resistance against radiotherapy and TMZ chemotherapy $[3,65,66]$. Moreover, TMs drive glioma cell invasion in the brain. An increased glioma cell invasiveness that can occur during inhibition of angiogenesis has been proposed as one major mechanism of resistance against antiangiogenics [33-36], although this could not be clearly demonstrated in patients yet [67]. Finally, it is very well possible that other well-described effects of antiangiogenics and/or cytotoxic therapies, like modulation of the immune tumor microenvironment and DNA damage response, play a role here. Our study provides the first evidence that antiangiogenic agents can even decrease cellular resistance mechanisms of glioma cells, but only if the right cytotoxic combination partner is selected.

In summary, we provide evidence that inhibition of VEGF-A might be the best combination strategy for radiotherapy, but inhibition of both Ang-2 and VEGF-A for chemotherapy. This provides interesting cues how to best develop dual anti-Ang-2/VEGF-A inhibitors in the clinic: combination with chemotherapy (either adjuvant TMZ in newly diagnosed glioblastoma or lomustine in recurrent glioblastoma) appears the most promising clinical trial strategy, while combination with radiotherapy might even be avoided. Since all phase III studies in primary or recurrent glioblastoma did not find unexpected CNS toxicities or other toxicities when the anti-VEGF-A antibody bevacizumab was combined with chemo-/radiotherapy (Chinot et al. 2014; Gilbert et al. 2014; Wick et al. 2017 [21-23]), at least safety and tolerability seem to not be a major issue with these treatment strategies. The most important consequence of the surprisingly complex interactions between antiangiogenic and cytotoxic treatments reported here is to better study them in preclinical and early clinical settings in the future to avoid testing uninformed combination regimens in controlled clinical trials.

\section{Materials and Methods}

\subsection{Cell Culture}

Cell culture was done under adherent conditions with Dulbeccos's Modified Eagle's Medium (DMEM, Sigma-Aldrich, Munich, Germany), which was supplemented with 10\% fetal bovine serum (FBS, Sigma-Aldrich, Munich, Germany) and 1\% penicillin-streptomycin (PS, Sigma-Aldrich, Munich, 
Germany). For the cultured cells a contamination and authentification test was done by Multiplexion (Heidelberg, Germany). U-87MG, a human glioblastoma cell line obtained from the American Type Culture Collection (LGC Standards, Wesel, Germany), which is growing angiogenic in the mouse brain was used. $\mathrm{O}^{6}$-methylguanine-DNA methyltransferase (MGMT) promotor methylation of this cell line was already confirmed in former publications [68]. Furthermore, when 24 brain tumor cell lines were analyzed for VEGF-A and Ang-2 mRNA expression, the U-87MG cell line showed both, being considerably representative with respect to expression levels. The cells were stably co-transduced with the red cytoplasmic construct LeGO-T2 (plasmid \#27342 Addgene, Cambridge, MA, USA) and the green nuclear fluorescent plasmid LV-GFP (plasmid \#25999 Addgene, Cambridge, MA, USA). The co-transduced cells were selected by fluorescence-associated cell sorting (FACSAria ${ }^{\mathrm{TM}}$ Special Order System, BD Biosciences, Heidelberg, Germany). To distinguish between single and double transduced cells, compensation was used. To separate dead and alive cells, propidium iodide (Sigma-Aldrich, Munich, Germany) staining was used.

\subsection{Animals and Surgical Procedures}

Naval Medical Research Institute (NMRI) nude male mice, between 8 and 10 weeks old (Charles River, Sulzfeld, Germany) were used to study the angiogenesis of human brain tumor cells within the mouse brain. All efforts were made to minimize animal suffering and to reduce the number of animals used. The operation of the chronic cranial window was done as previously described [3,69]. One week after window implantation a $1 \mu \mathrm{L}$ cell suspension, containing 50,000 tumor cells, was injected cortically $500 \mu \mathrm{m}$ deep with a stereotactical injector (Hamilton, Bonaduz, Switzerland and Stoelting, Wood Dale, IL, USA). When the tumor reached a mean diameter of $2 \mathrm{~mm}$ in vivo imaging and therapy was started. The animals were sacrificed when they got moribund and/or developed a weight loss of over $20 \%$, which was particularly important in light of the frequent intravital imaging sessions that were an additional burden for tumor-bearing mice. The animals were treated every third day with the control (MOPC21), the anti-Ang-2 (LC06, RO6872894), the anti-VEGF-A (B20.4.1, RO6872895), or the anti-Ang-2/VEGF-A antibodies (LC06/B20.4.1, RO6872840) (F. Hoffmann-La Roche, Penzberg, Germany). All antibodies were administered in the same concentration of $5 \mathrm{mg} / \mathrm{kg}$ body weight (bw). For the radiotherapy group, tumors were irradiated with 7 Gy on D4, D5, and D6 (three consecutive days; total dose $21 \mathrm{~Gy}$ ) after the start of the antiangiogenic treatment. The radiation was done with a $6 \mathrm{MV}$ linear accelerator with a $6 \mathrm{~mm}$ collimator (adjusted to the window size) at a dose rate of $3 \mathrm{~Gy} \mathrm{~min}^{-1}$ (Artiste, Siemens, Erlangen, Germany). The administered radiation dose is in the range of the commonly used $60 \mathrm{~Gy}$ in 2 Gy fractions for glioma patients, assuming an $\alpha / \beta$ of $\sim 10$ in the linear quadratic model, and taking into account a radiation time of three days (Osswald et al. 2015; Winkler et al. 2004 [3,6]). For the chemotherapy group, animals were orally administered with TMZ (Schering-Plough, Kenilworth, NJ, USA) using a feeding needle on the three consecutive days during D4-D6 of therapy. TMZ concentration was $20 \mathrm{mg} / \mathrm{kg}$ bw per day (Figure S3A,B). This dose was selected because it was shown to exert measurable anti-tumor effects as single agent in preliminary studies on U87 and other glioma models (Weil et al. 2017 [65]) in our laboratory, but still low enough to be comparable to bioavailable doses given to patients. All animal procedures were performed in accordance with the institutional laboratory animal research guidelines after approval of the Regierungspräsidium Karlsruhe, Germany (governmental authority).

\subsection{In Vivo Multiphoton Laser Scanning Microscopy (MPLSM)}

In vivo imaging was performed with a LSM 7MP microscope (Carl Zeiss Microscopy, Jena, Germany) provided with a Coherent Chameleon UltraII laser (Coherent, Glasgow, UK) with a $500-550 \mathrm{~nm}$ and a $575-610 \mathrm{~nm}$ band pass filter. With the following wavelengths fluorophores were detected: $750 \mathrm{~nm}$ (FITC-dextrane, tdTomato) and $850 \mathrm{~nm}$ (GFP, TRITC-dextrane). To prevent phototoxic effects laser power was always kept as low as possible. During the imaging process animals were anaesthetized with a low gas narcosis including 1.5\% isoflurane (Baxter, Unterschleißheim, 
Germany) and 98.5\% oxygen (Guttroff, Heidelberg, Germany). During imaging body temperature was kept constantly at $37^{\circ} \mathrm{C}$ by a heating pad. To acquire angiographies of brain blood vessel, $0.1 \mathrm{~mL}$ high molecular dextrans were injected intravenously: tetramethylrhodamine isothiocyanate (TRITC, $500 \mathrm{kDa}, 10 \mathrm{mg} \mathrm{mL}^{-1}$, Sigma-Aldrich, Munich, Germany), and fluorescein isothiocyanate (FITC, $2 \mathrm{MDa}, 10 \mathrm{mg} \mathrm{mL}^{-1}$, Sigma-Aldrich, Munich, Germany). The angiographic image (size: $607.28 \times$ $607.28 \times 123 \mu \mathrm{m}$ ) allowed longitudinal tracking of two consecutive regions in the center of the brain tumor, which was done every third day from D0 to D15 after beginning with antiangiogenic treatment.

The large cranial window also allowed to study the entire tumor up to a depth of up to $1000 \mu \mathrm{m}$ that sufficiently allowed to assess the tumor diameter. Verification experiments were performed, comparing the diameter measured by in vivo two-photon microscopy with the maximum diameter measured by standard histology and fluorescence microscopy of tumor-bearing brain sections. Here, a strong correlation was detected [7]. The mean tumor diameter under the cranial window was measured by a tile scan in a depth of $400 \mu \mathrm{m}$.

On D0 and D6, microvascular blood flow velocity was measured by a line scan as described before [7]. The cellular morphology and the length of the TMs were determined in a depth of $51 \mu \mathrm{m}$ on D0, D9, and D28. On D3, D9, and D15 the nuclei were detected with a higher magnification (size: $151.82 \times 151.82 \times 48 \mu \mathrm{m}$ ) to quantify the nuclear density and the nuclear morphology. Additionally, the nuclear motility of the cells of the same region (size: $151.82 \times 151.82 \times 99 \mu \mathrm{m}$ ) was measured over $1.5 \mathrm{~h}$.

\subsection{Quantification and Visualization of MPLSM Data}

In vivo images were recorded with the ZEN Software (Carl Zeiss Microscopy, Jena, Germany). Images were analyzed with the ImageJ $1.51 \mathrm{f}$ software (Wayne Rasband, National Institutes of Health, Bethesda, MD, USA). The diameter was determined by a tile scan in a depth of about $400 \mu \mathrm{m}$, where the tumor bulk reached its major dimensions. The diameter was calculated as the average of the minor and major axis of an ellipse. For quantification the diameters were normalized to the mean diameter on D0.

The blood flow velocity was measured by a line scan with a minimum length of $10 \mu \mathrm{m}$, detecting 2000 events in microvessels. Moreover, 16 randomly chosen vessels were measured per animal. The resulting scan identifies single erythrocytes as angular black lines, where the $\mathrm{x}$-axis is according to the length of the detected distance and the y-axis is the elapsed time of the measurement. The angle is converging more and more to $90^{\circ}$ when the cells are static. By knowing the resolution of both parameters and by the measurement of the slope of 30 randomly chosen red blood cells, a calculation of the mean velocity is possible, by inversion of the result.

For the nuclear density and the quantification of mitotic cells, stacks cropped to thickness of $67 \mu \mathrm{m}$ $(151.82 \times 151.82 \mu \mathrm{m})$ in a depth of 35-102 $\mu \mathrm{m}$ were analyzed. The nuclear density was calculated by dividing the manually counted cell number with the volume of the stack. For the quantification of the mitotic activity, the percentage of mitotic cells was detected. Due to distances up to $100 \mu \mathrm{m}$ between vessels and pathological nuclei, the whole and not the cropped stacks were analyzed manually. In control animals, nuclear size and shape was very homogenous. In distinct treatment groups, nuclear morphological changes of apoptosis or necrosis where evident. Tortuous, abnormally flexed, strongly condensed or swollen nuclei were evaluated as pathological (see Figure 3A). The distance between the center of the pathological nucleus and the exterior of the wall of the blood vessels was measured manually.

TMs were identified as thin and long cytoplasmatic protrusions, which often interconnect tumor cells [3]. For the measurement of the TM length single slices in a depth of $51 \mu \mathrm{m}$ were quantified for two regions per animal. For every region 30 random cells were picked, where the length of the longest and most prominent TM of the cell was determined.

Cellular invasiveness was detected for 3D stacks in a depth of 51-150 $\mu \mathrm{m}$, which were recorded in 40 cycles long (over $1.5 \mathrm{~h}$ lasting) time series. For 20 randomly chosen nuclei, $\mathrm{x}, \mathrm{y}$, and $\mathrm{z}$ coordinates 
were identified for 10 different time points. Since the expansion of the tissue by laser irradiation and breathing artefacts also modifies coordinates, striking blood vessel bifurcations were used as an inertial system.

$3 \mathrm{D}$ representative pictures for the angiograms, nuclear morphologies, nuclear densities, nuclear motilities and the 3D rendering of the TMs were acquired with Imaris 7.5.1 (Bitplane, Zürich, Switzerland). Finally, the pictures were edited with Inkscape 0.91 (GNU General Public License) and GIMP 2.8.14 (GNU General Public License).

\subsection{Statistical Analysis}

The measured results were arranged in Excel 2016 (Microsoft Corporation, Redmond, WA, USA) and tested for outliers by a Nalimov test. The outlier-cleared datasets were transferred to the statistic software SigmaPlot 13.0 (Systat Software, San Jose, CA, USA). Equal variance and normal distribution were tested (Kolmogorov-Smirnov or Shapiro-Wilk). For results with normal distribution and equal variance, the two-sided Student's $t$-test was used. Otherwise, the Mann-Whitney U statistic was applied. For measurements with more than two groups, ANOVA on ranks or ANOVA was used in combination with the suitable post-hoc test (Dunn's method for the non-parametric and the Tukey test for the parametric). Results were significant from the corresponding control at a critical p-value below 0.05. Results were plotted in a line diagram by presenting the mean \pm standard error of mean (SEM). In a bar chart the results were displayed as mean \pm standard deviation (SD). Box plots depicted the median values with the percentiles and error bars. Results shown in a line diagram and in a bar chart have a linear scale; results in a box plot had a common logarithm scale for the ordinate. Finally, the pictures were finished with the graphic editors Inkscape 0.91 (GNU General Public License) and GIMP 2.8.14 (GNU General Public License).

\section{Conclusions}

Despite very high angiogenic activity of malignant gliomas, the current clinical effectiveness of antiangiogenic drugs and their combination regimens falls short of expectations. Here we show that inhibition of VEGF-A might be the best combination strategy for radiotherapy, but dual inhibition of Ang-2 plus VEGF-A for chemotherapy. This provides interesting cues how to best develop dual anti-Ang-2/VEGF-A inhibitors in the clinic. Combination with chemotherapy (either with adjuvant TMZ in primary glioblastoma, or lomustine in recurrent glioblastoma) appears most promising. Remarkably, the VEGF-A blocking antibody bevacizumab has never been tested with radiotherapy alone in a controlled clinical trial, which might be its optimal combination partner according to the results of this study. The most important consequence of the surprisingly complex interactions between antiangiogenic and cytotoxic treatments is to better study them in preclinical and early clinical settings in the future - to avoid testing uninformed combination regimens in controlled clinical trials.

Supplementary Materials: The following are available online at http:/ /www.mdpi.com/2072-6694/11/3/314/s1, Figure S1: Experimental design, Figure S2: Differential changes of tumor blood vessel angiograms during combination of antiangiogenic treatment with radio- or chemotherapy, Figure S3: Transient pro-mitotic effects, and nuclear densities.

Author Contributions: G.S., M.O., H.-J.M., O.K., Y.K., W.W. and F.W. were responsible for experimental design, data interpretation, and writing of the manuscript. G.S. performed cell culture, surgical procedures, and MPLSM experiments. D.W. and M.G. performed cell culture experiments and surgical procedures. M.R. performed cell culture and was responsible for writing the manuscript.

Funding: Research grant from F. Hoffmann-La Roche AG to F.W.; research funding from Apogenix, Boehringer Ingelheim, MSD, Roche and Pfizer to W.W.

Acknowledgments: We would like to thank Christiane Stahl-Arnsberger, Peter Häring, Clemens Lang, Vanessa Mendes, and Mona Splinter for the irradiation of the mice; Felix Bestvater, Gaby Blaser, Manuela Brom, and Damir Krunic for assistance with the confocal microscope; Miriam Gömmel for the preparation of cranial windows; Mostafa Jarahian for FACS sorting of transduced cells; Anna S. Berghoff, Sara Ciprut, and Tobias Kessler for proofreading of the publication. 
Conflicts of Interest: G.S. is an employee of Carl Zeiss Microscopy GmbH. H.-J.M., O.K. and Y.K. are employees of F. Hoffmann-La Roche AG. W.W. has participated in a speaker's bureau for BMS, Genentech/Roche and MSD, he received research funding from Apogenix, Boehringer Ingelheim, Merck, Sharp, and Dohme (MSD), Roche and Pfizer and has a consultant relationship with BMS, Genentech/Roche and MSD. F.W. received research grants from F. Hoffmann-La Roche AG, Boehringer, Glaxo Smith Kline, and Genentech.

\section{References}

1. Louis, D.N.; Perry, A.; Reifenberger, G.; von Deimling, A.; Figarella-Branger, D.; Cavenee, W.K.; Ohgaki, H.; Wiestler, O.D.; Kleihues, P.; Ellison, D.W. The 2016 World Health Organization Classification of Tumors of the Central Nervous System: A summary. Acta Neuropathol. 2016, 131, 803-820. [CrossRef] [PubMed]

2. Stupp, R.; Mason, W.P.; van den Bent, M.J.; Weller, M.; Fisher, B.; Taphoorn, M.J.; Belanger, K.; Brandes, A.A.; Marosi, C.; Bogdahn, U.; et al. Radiotherapy plus concomitant and adjuvant temozolomide for glioblastoma. N. Engl. J. Med. 2005, 352, 987-996. [CrossRef] [PubMed]

3. Osswald, M.; Jung, E.; Sahm, F.; Solecki, G.; Venkataramani, V.; Blaes, J.; Weil, S.; Horstmann, H.; Wiestler, B.; Syed, M.; et al. Brain tumour cells interconnect to a functional and resistant network. Nature 2015, 528, 93-98. [CrossRef] [PubMed]

4. Wick, W.; Platten, M.; Wick, A.; Hertenstein, A.; Radbruch, A.; Bendszus, M.; Winkler, F. Current status and future directions of anti-angiogenic therapy for gliomas. Neuro Oncol. 2016, 18, 315-328. [CrossRef] [PubMed]

5. Osswald, M.; Solecki, G.; Wick, W.; Winkler, F. A malignant cellular network in gliomas: Potential clinical implications. Neuro Oncol. 2016, 18, 479-485. [CrossRef] [PubMed]

6. Winkler, F.; Kozin, S.V.; Tong, R.T.; Chae, S.S.; Booth, M.F.; Garkavtsev, I.; Xu, L.; Hicklin, D.J.; Fukumura, D.; di Tomaso, E.; et al. Kinetics of vascular normalization by VEGFR2 blockade governs brain tumor response to radiation: Role of oxygenation, angiopoietin-1, and matrix metalloproteinases. Cancer Cell 2004, 6, 553-563. [CrossRef] [PubMed]

7. Von Baumgarten, L.; Brucker, D.; Tirniceru, A.; Kienast, Y.; Grau, S.; Burgold, S.; Herms, J.; Winkler, F. Bevacizumab has differential and dose-dependent effects on glioma blood vessels and tumor cells. Clin. Cancer Res. 2011, 17, 6192-6205. [CrossRef] [PubMed]

8. Plate, K.H.; Breier, G.; Weich, H.A.; Mennel, H.D.; Risau, W. Vascular endothelial growth factor and glioma angiogenesis: Coordinate induction of VEGF receptors, distribution of VEGF protein and possible in vivo regulatory mechanisms. Int. J. Cancer 1994, 59, 520-529. [CrossRef] [PubMed]

9. Scholz, A.; Harter, P.N.; Cremer, S.; Yalcin, B.H.; Gurnik, S.; Yamaji, M.; Di Tacchio, M.; Sommer, K.; Baumgarten, P.; Bahr, O.; et al. Endothelial cell-derived angiopoietin-2 is a therapeutic target in treatment-naive and bevacizumab-resistant glioblastoma. EMBO Mol. Med. 2016, 8, 39-57. [CrossRef] [PubMed]

10. Kloepper, J.; Riedemann, L.; Amoozgar, Z.; Seano, G.; Susek, K.; Yu, V.; Dalvie, N.; Amelung, R.L.; Datta, M.; Song, J.W.; et al. Ang-2/VEGF bispecific antibody reprograms macrophages and resident microglia to anti-tumor phenotype and prolongs glioblastoma survival. Proc. Natl. Acad. Sci. USA 2016, 113, 4476-4481. [CrossRef] [PubMed]

11. Peterson, T.E.; Kirkpatrick, N.D.; Huang, Y.; Farrar, C.T.; Marijt, K.A.; Kloepper, J.; Datta, M.; Amoozgar, Z.; Seano, G.; Jung, K.; et al. Dual inhibition of Ang-2 and VEGF receptors normalizes tumor vasculature and prolongs survival in glioblastoma by altering macrophages. Proc. Natl. Acad. Sci. USA 2016, 113, 4470-4475. [CrossRef] [PubMed]

12. Stratmann, A.; Risau, W.; Plate, K.H. Cell type-specific expression of angiopoietin-1 and angiopoietin-2 suggests a role in glioblastoma angiogenesis. Am. J. Pathol. 1998, 153, 1459-1466. [CrossRef]

13. Chae, S.S.; Kamoun, W.S.; Farrar, C.T.; Kirkpatrick, N.D.; Niemeyer, E.; de Graaf, A.M.; Sorensen, A.G.; Munn, L.L.; Jain, R.K.; Fukumura, D. Angiopoietin-2 interferes with anti-VEGFR2-induced vessel normalization and survival benefit in mice bearing gliomas. Clin. Cancer Res. 2010, 16, 3618-3627. [CrossRef] [PubMed]

14. Jain, R.K. Normalization of tumor vasculature: An emerging concept in antiangiogenic therapy. Science 2005, 307, 58-62. [CrossRef] [PubMed] 
15. Huber, P.E.; Bischof, M.; Jenne, J.; Heiland, S.; Peschke, P.; Saffrich, R.; Grone, H.J.; Debus, J.; Lipson, K.E.; Abdollahi, A. Trimodal cancer treatment: Beneficial effects of combined antiangiogenesis, radiation, and chemotherapy. Cancer Res. 2005, 65, 3643-3655. [CrossRef] [PubMed]

16. Sorensen, A.G.; Batchelor, T.T.; Zhang, W.T.; Chen, P.J.; Yeo, P.; Wang, M.; Jennings, D.; Wen, P.Y.; Lahdenranta, J.; Ancukiewicz, M.; et al. A "vascular normalization index" as potential mechanistic biomarker to predict survival after a single dose of cediranib in recurrent glioblastoma patients. Cancer Res. 2009, 69, 5296-5300. [CrossRef] [PubMed]

17. McGee, M.C.; Hamner, J.B.; Williams, R.F.; Rosati, S.F.; Sims, T.L.; Ng, C.Y.; Gaber, M.W.; Calabrese, C.; Wu, J.; Nathwani, A.C.; et al. Improved intratumoral oxygenation through vascular normalization increases glioma sensitivity to ionizing radiation. Int. J. Radiat. Oncol. Biol. Phys. 2010, 76, 1537-1545. [CrossRef] [PubMed]

18. Jain, R.K. Normalizing tumor vasculature with anti-angiogenic therapy: A new paradigm for combination therapy. Nat. Med. 2001, 7, 987-989. [CrossRef] [PubMed]

19. Jain, R.K.; Martin, J.D.; Stylianopoulos, T. The role of mechanical forces in tumor growth and therapy. Annu. Rev. Biomed. Eng. 2014, 16, 321-346. [CrossRef] [PubMed]

20. Batchelor, T.T.; Gerstner, E.R.; Emblem, K.E.; Duda, D.G.; Kalpathy-Cramer, J.; Snuderl, M.; Ancukiewicz, M.; Polaskova, P.; Pinho, M.C.; Jennings, D.; et al. Improved tumor oxygenation and survival in glioblastoma patients who show increased blood perfusion after cediranib and chemoradiation. Proc. Natl. Acad. Sci. USA 2013, 110, 19059-19064. [CrossRef] [PubMed]

21. Gilbert, M.R.; Dignam, J.J.; Armstrong, T.S.; Wefel, J.S.; Blumenthal, D.T.; Vogelbaum, M.A.; Colman, H.; Chakravarti, A.; Pugh, S.; Won, M.; et al. A randomized trial of bevacizumab for newly diagnosed glioblastoma. N. Engl. J. Med. 2014, 370, 699-708. [CrossRef] [PubMed]

22. Chinot, O.L.; Wick, W.; Mason, W.; Henriksson, R.; Saran, F.; Nishikawa, R.; Carpentier, A.F.; Hoang-Xuan, K.; Kavan, P.; Cernea, D.; et al. Bevacizumab plus radiotherapy-temozolomide for newly diagnosed glioblastoma. N. Engl. J. Med. 2014, 370, 709-722. [CrossRef] [PubMed]

23. Wick, W.; Gorlia, T.; Bendszus, M.; Taphoorn, M.; Sahm, F.; Harting, I.; Brandes, A.A.; Taal, W.; Domont, J.; Idbaih, A.; et al. Lomustine and Bevacizumab in Progressive Glioblastoma. N. Engl. J. Med. 2017, 377, 1954-1963. [CrossRef] [PubMed]

24. Sandmann, T.; Bourgon, R.; Garcia, J.; Li, C.; Cloughesy, T.; Chinot, O.L.; Wick, W.; Nishikawa, R.; Mason, W.; Henriksson, R.; et al. Patients With Proneural Glioblastoma May Derive Overall Survival Benefit From the Addition of Bevacizumab to First-Line Radiotherapy and Temozolomide: Retrospective Analysis of the AVAglio Trial. J. Clin. Oncol. 2015, 33, 2735-2744. [CrossRef] [PubMed]

25. Kessler, T.; Sahm, F.; Blaes, J.; Osswald, M.; Rubmann, P.; Milford, D.; Urban, S.; Jestaedt, L.; Heiland, S.; Bendszus, M.; et al. Glioma cell VEGFR-2 confers resistance to chemotherapeutic and antiangiogenic treatments in PTEN-deficient glioblastoma. Oncotarget 2015, 6, 31050-31068. [CrossRef] [PubMed]

26. Kienast, Y.; Klein, C.; Scheuer, W.; Raemsch, R.; Lorenzon, E.; Bernicke, D.; Herting, F.; Yu, S.; The, H.H.; Martarello, L.; et al. Ang-2-VEGF-A CrossMab, a novel bispecific human IgG1 antibody blocking VEGF-A and Ang-2 functions simultaneously, mediates potent antitumor, antiangiogenic, and antimetastatic efficacy. Clin. Cancer Res. 2013, 19, 6730-6740. [CrossRef] [PubMed]

27. Thomas, M.; Kienast, Y.; Scheuer, W.; Bahner, M.; Kaluza, K.; Gassner, C.; Herting, F.; Brinkmann, U.; Seeber, S.; Kavlie, A.; et al. A novel angiopoietin-2 selective fully human antibody with potent anti-tumoral and anti-angiogenic efficacy and superior side effect profile compared to Pan-Angiopoietin-1/-2 inhibitors. PLoS ONE 2013, 8, e54923. [CrossRef] [PubMed]

28. Liang, W.C.; Wu, X.; Peale, F.V.; Lee, C.V.; Meng, Y.G.; Gutierrez, J.; Fu, L.; Malik, A.K.; Gerber, H.P.; Ferrara, N.; et al. Cross-species vascular endothelial growth factor (VEGF)-blocking antibodies completely inhibit the growth of human tumor xenografts and measure the contribution of stromal VEGF. J. Biol. Chem. 2006, 281, 951-961. [CrossRef] [PubMed]

29. Baker, L.C.; Boult, J.K.; Thomas, M.; Koehler, A.; Nayak, T.; Tessier, J.; Ooi, C.H.; Birzele, F.; Belousov, A.; Zajac, M.; et al. Acute tumour response to a bispecific Ang-2-VEGF-A antibody: Insights from multiparametric MRI and gene expression profiling. Br. J. Cancer 2016, 115, 691-702. [CrossRef] [PubMed]

30. Klein, C.; Schaefer, W.; Regula, J.T. The use of CrossMAb technology for the generation of bi- and multispecific antibodies. $m A$ bs 2016, 8, 1010-1020. [CrossRef] [PubMed] 
31. Schaefer, W.; Regula, J.T.; Bahner, M.; Schanzer, J.; Croasdale, R.; Durr, H.; Gassner, C.; Georges, G.; Kettenberger, H.; Imhof-Jung, S.; et al. Immunoglobulin domain crossover as a generic approach for the production of bispecific IgG antibodies. Proc. Natl. Acad. Sci. USA 2011, 108, 11187-11192. [CrossRef] [PubMed]

32. Kamoun, W.S.; Chae, S.S.; Lacorre, D.A.; Tyrrell, J.A.; Mitre, M.; Gillissen, M.A.; Fukumura, D.; Jain, R.K.; Munn, L.L. Simultaneous measurement of RBC velocity, flux, hematocrit and shear rate in vascular networks. Nat. Methods 2010, 7, 655-660. [CrossRef] [PubMed]

33. Lu, K.V.; Chang, J.P.; Parachoniak, C.A.; Pandika, M.M.; Aghi, M.K.; Meyronet, D.; Isachenko, N.; Fouse, S.D.; Phillips, J.J.; Cheresh, D.A.; et al. VEGF inhibits tumor cell invasion and mesenchymal transition through a MET/VEGFR2 complex. Cancer Cell 2012, 22, 21-35. [CrossRef] [PubMed]

34. Fischer, I.; Cunliffe, C.H.; Bollo, R.J.; Raza, S.; Monoky, D.; Chiriboga, L.; Parker, E.C.; Golfinos, J.G.; Kelly, P.J.; Knopp, E.A.; et al. High-grade glioma before and after treatment with radiation and Avastin: Initial observations. Neuro Oncol. 2008, 10, 700-708. [CrossRef] [PubMed]

35. Paez-Ribes, M.; Allen, E.; Hudock, J.; Takeda, T.; Okuyama, H.; Vinals, F.; Inoue, M.; Bergers, G.; Hanahan, D.; Casanovas, O. Antiangiogenic therapy elicits malignant progression of tumors to increased local invasion and distant metastasis. Cancer Cell 2009, 15, 220-231. [CrossRef] [PubMed]

36. Keunen, O.; Johansson, M.; Oudin, A.; Sanzey, M.; Rahim, S.A.; Fack, F.; Thorsen, F.; Taxt, T.; Bartos, M.; Jirik, R.; et al. Anti-VEGF treatment reduces blood supply and increases tumor cell invasion in glioblastoma. Proc. Natl. Acad. Sci. USA 2011, 108, 3749-3754. [CrossRef] [PubMed]

37. Labussiere, M.; Cheneau, C.; Prahst, C.; Gallego Perez-Larraya, J.; Farina, P.; Lombardi, G.; Mokhtari, K.; Rahimian, A.; Delattre, J.Y.; Eichmann, A.; et al. Angiopoietin-2 May Be Involved in the Resistance to Bevacizumab in Recurrent Glioblastoma. Cancer Investig. 2016, 34, 39-44. [CrossRef] [PubMed]

38. Cortes-Santiago, N.; Hossain, M.B.; Gabrusiewicz, K.; Fan, X.; Gumin, J.; Marini, F.C.; Alonso, M.M.; Lang, F.; Yung, W.K.; Fueyo, J.; et al. Soluble Tie2 overrides the heightened invasion induced by anti-angiogenesis therapies in gliomas. Oncotarget 2016, 7, 16146-16157. [CrossRef] [PubMed]

39. Tong, R.T.; Boucher, Y.; Kozin, S.V.; Winkler, F.; Hicklin, D.J.; Jain, R.K. Vascular normalization by vascular endothelial growth factor receptor 2 blockade induces a pressure gradient across the vasculature and improves drug penetration in tumors. Cancer Res. 2004, 64, 3731-3736. [CrossRef] [PubMed]

40. Grossman, R.; Brastianos, H.; Blakeley, J.O.; Mangraviti, A.; Lal, B.; Zadnik, P.; Hwang, L.; Wicks, R.T.; Goodwin, R.C.; Brem, H.; et al. Combination of anti-VEGF therapy and temozolomide in two experimental human glioma models. J. Neuro Oncol. 2014, 116, 59-65. [CrossRef] [PubMed]

41. Van der Veldt, A.A.; Lubberink, M.; Bahce, I.; Walraven, M.; de Boer, M.P.; Greuter, H.N.; Hendrikse, N.H.; Eriksson, J.; Windhorst, A.D.; Postmus, P.E.; et al. Rapid decrease in delivery of chemotherapy to tumors after anti-VEGF therapy: Implications for scheduling of anti-angiogenic drugs. Cancer Cell 2012, 21, 82-91. [CrossRef] [PubMed]

42. Rohrig, F.; Vorlova, S.; Hoffmann, H.; Wartenberg, M.; Escorcia, F.E.; Keller, S.; Tenspolde, M.; Weigand, I.; Gatzner, S.; Manova, K.; et al. VEGF-ablation therapy reduces drug delivery and therapeutic response in ECM-dense tumors. Oncogene 2016, 36. [CrossRef] [PubMed]

43. Ma, J.; Waxman, D.J. Modulation of the antitumor activity of metronomic cyclophosphamide by the angiogenesis inhibitor axitinib. Mol. Cancer Ther. 2008, 7, 79-89. [CrossRef] [PubMed]

44. Arjaans, M.; Schroder, C.P.; Oosting, S.F.; Dafni, U.; Kleibeuker, J.E.; de Vries, E.G. VEGF pathway targeting agents, vessel normalization and tumor drug uptake: From bench to bedside. Oncotarget 2016, 7, 21247-21258. [CrossRef] [PubMed]

45. Agarwala, S.S.; Kirkwood, J.M. Temozolomide, a novel alkylating agent with activity in the central nervous system, may improve the treatment of advanced metastatic melanoma. Oncologist 2000, 5, 144-151. [CrossRef] [PubMed]

46. Baumert, B.G.; Hegi, M.E.; van den Bent, M.J.; von Deimling, A.; Gorlia, T.; Hoang-Xuan, K.; Brandes, A.A.; Kantor, G.; Taphoorn, M.J.; Hassel, M.B.; et al. Temozolomide chemotherapy versus radiotherapy in high-risk low-grade glioma (EORTC 22033-26033): A randomised, open-label, phase 3 intergroup study. Lancet Oncol. 2016, 17, 1521-1532. [CrossRef]

47. Winkler, F.; Osswald, M.; Wick, W. Anti-Angiogenics: Their Role in the Treatment of Glioblastoma. Oncol. Res. Treat. 2018, 41, 181-186. [CrossRef] [PubMed] 
48. Lange, C.; Storkebaum, E.; de Almodovar, C.R.; Dewerchin, M.; Carmeliet, P. Vascular endothelial growth factor: A neurovascular target in neurological diseases. Nat. Rev. Neurol. 2016, 12, 439-454. [CrossRef] [PubMed]

49. Jayson, G.C.; Kerbel, R.; Ellis, L.M.; Harris, A.L. Antiangiogenic therapy in oncology: Current status and future directions. Lancet 2016, 388, 518-529. [CrossRef]

50. Bergers, G.; Hanahan, D. Modes of resistance to anti-angiogenic therapy. Nat. Rev. Cancer 2008, 8, $592-603$. [CrossRef] [PubMed]

51. Thomas, M.; Felcht, M.; Kruse, K.; Kretschmer, S.; Deppermann, C.; Biesdorf, A.; Rohr, K.; Benest, A.V.; Fiedler, U.; Augustin, H.G. Angiopoietin-2 stimulation of endothelial cells induces alphavbeta3 integrin internalization and degradation. J. Biol. Chem. 2010, 285, 23842-23849. [CrossRef] [PubMed]

52. Scharpfenecker, M.; Fiedler, U.; Reiss, Y.; Augustin, H.G. The Tie-2 ligand angiopoietin-2 destabilizes quiescent endothelium through an internal autocrine loop mechanism. J. Cell Sci. 2005, 118, 771-780. [CrossRef] [PubMed]

53. Felcht, M.; Luck, R.; Schering, A.; Seidel, P.; Srivastava, K.; Hu, J.; Bartol, A.; Kienast, Y.; Vettel, C.; Loos, E.K.; et al. Angiopoietin-2 differentially regulates angiogenesis through TIE2 and integrin signaling. J. Clin. Investig. 2012, 122, 1991-2005. [CrossRef] [PubMed]

54. Bessho, H.; Wong, B.; Huang, D.; Tan, J.; Ong, C.K.; Iwamura, M.; Hart, S.; Dangl, M.; Thomas, M.; Teh, B.T. Effect of Ang-2-VEGF-A Bispecific Antibody in Renal Cell Carcinoma. Cancer Investig. 2015, 33, 378-386. [CrossRef] [PubMed]

55. Brown, J.L.; Cao, Z.A.; Pinzon-Ortiz, M.; Kendrew, J.; Reimer, C.; Wen, S.; Zhou, J.Q.; Tabrizi, M.; Emery, S.; McDermott, B.; et al. A human monoclonal anti-ANG2 antibody leads to broad antitumor activity in combination with VEGF inhibitors and chemotherapy agents in preclinical models. Mol. Cancer Ther. 2010, 9 , 145-156. [CrossRef] [PubMed]

56. Daly, C.; Eichten, A.; Castanaro, C.; Pasnikowski, E.; Adler, A.; Lalani, A.S.; Papadopoulos, N.; Kyle, A.H.; Minchinton, A.I.; Yancopoulos, G.D.; et al. Angiopoietin-2 functions as a Tie2 agonist in tumor models, where it limits the effects of VEGF inhibition. Cancer Res. 2013, 73, 108-118. [CrossRef] [PubMed]

57. Hashizume, H.; Falcon, B.L.; Kuroda, T.; Baluk, P.; Coxon, A.; Yu, D.; Bready, J.V.; Oliner, J.D.; McDonald, D.M. Complementary actions of inhibitors of angiopoietin-2 and VEGF on tumor angiogenesis and growth. Cancer Res. 2010, 70, 2213-2223. [CrossRef] [PubMed]

58. Koh, Y.J.; Kim, H.Z.; Hwang, S.I.; Lee, J.E.; Oh, N.; Jung, K.; Kim, M.; Kim, K.E.; Kim, H.; Lim, N.K.; et al. Double antiangiogenic protein, DAAP, targeting VEGF-A and angiopoietins in tumor angiogenesis, metastasis, and vascular leakage. Cancer Cell 2010, 18, 171-184. [CrossRef] [PubMed]

59. Myers, A.L.; Williams, R.F.; Ng, C.Y.; Hartwich, J.E.; Davidoff, A.M. Bevacizumab-induced tumor vessel remodeling in rhabdomyosarcoma xenografts increases the effectiveness of adjuvant ionizing radiation. J. Pediatr. Surg. 2010, 45, 1080-1085. [CrossRef] [PubMed]

60. Browder, T.; Butterfield, C.E.; Kraling, B.M.; Shi, B.; Marshall, B.; O’Reilly, M.S.; Folkman, J. Antiangiogenic scheduling of chemotherapy improves efficacy against experimental drug-resistant cancer. Cancer Res. 2000, 60, 1878-1886. [PubMed]

61. Kerbel, R.S.; Kamen, B.A. The anti-angiogenic basis of metronomic chemotherapy. Nat. Rev. Cancer 2004, 4, 423-436. [CrossRef] [PubMed]

62. Goel, S.; Duda, D.G.; Xu, L.; Munn, L.L.; Boucher, Y.; Fukumura, D.; Jain, R.K. Normalization of the vasculature for treatment of cancer and other diseases. Physiol. Rev. 2011, 91, 1071-1121. [CrossRef] [PubMed]

63. Wild-Bode, C.; Weller, M.; Rimner, A.; Dichgans, J.; Wick, W. Sublethal irradiation promotes migration and invasiveness of glioma cells: Implications for radiotherapy of human glioblastoma. Cancer Res. 2001, 61, 2744-2750. [PubMed]

64. Pei, J.; Park, I.H.; Ryu, H.H.; Li, S.Y.; Li, C.H.; Lim, S.H.; Wen, M.; Jang, W.Y.; Jung, S. Sublethal dose of irradiation enhances invasion of malignant glioma cells through p53-MMP 2 pathway in U87MG mouse brain tumor model. Radiat. Oncol. 2015, 10, 164. [CrossRef] [PubMed]

65. Weil, S.; Osswald, M.; Solecki, G.; Grosch, J.; Jung, E.; Lemke, D.; Ratliff, M.; Hanggi, D.; Wick, W.; Winkler, F. Tumor microtubes convey resistance to surgical lesions and chemotherapy in gliomas. Neuro Oncol. 2017, 19, 1316-1326. [CrossRef] [PubMed] 
66. Lou, E. Can you hear them now? Tumor microtubes form cellular communication networks that protect gliomas from surgical lesions and chemotherapy treatments. Neuro Oncol. 2017, 19, 1289-1291. [CrossRef] [PubMed]

67. Wick, A.; Dorner, N.; Schafer, N.; Hofer, S.; Heiland, S.; Schemmer, D.; Platten, M.; Weller, M.; Bendszus, M.; Wick, W. Bevacizumab does not increase the risk of remote relapse in malignant glioma. Ann. Neurol. 2011, 69, 586-592. [CrossRef] [PubMed]

68. Pyko, I.V.; Nakada, M.; Sabit, H.; Teng, L.; Furuyama, N.; Hayashi, Y.; Kawakami, K.; Minamoto, T.; Fedulau, A.S.; Hamada, J. Glycogen synthase kinase 3beta inhibition sensitizes human glioblastoma cells to temozolomide by affecting O6-methylguanine DNA methyltransferase promoter methylation via c-Myc signaling. Carcinogenesis 2013, 34, 2206-2217. [CrossRef] [PubMed]

69. Yuan, F.; Salehi, H.A.; Boucher, Y.; Vasthare, U.S.; Tuma, R.F.; Jain, R.K. Vascular permeability and microcirculation of gliomas and mammary carcinomas transplanted in rat and mouse cranial windows. Cancer Res. 1994, 54, 4564-4568. [PubMed]

(c) 2019 by the authors. Licensee MDPI, Basel, Switzerland. This article is an open access article distributed under the terms and conditions of the Creative Commons Attribution (CC BY) license (http://creativecommons.org/licenses/by/4.0/). 